\title{
EFFECT OF A TELEPHONIC INTERVENTION ON THE ADHERENCE OF PATIENTS WITH HYPERTENSION
}

\begin{abstract}
The effectiveness of a telephonic intervention in increasing patients' adherence to a health behaviour modification programme was tested. Patients were randomly assigned to two groups, the Experimental group receiving the telephonic intervention. Patients in the Experimental group showed greater adherence to the programme than the Control group $(p=0.007)$. Their knowledge of hypertension improved $(p=0.001)$ and was better than the control group $(p=0.03)$, their exercise capacity improved

STEWART AV, MSc (Physiotherapy)'; EALES CJ, PhD'; DAVIS KA, BSc (Physiotherapy) ${ }^{1}$

${ }^{1}$ Department of Physiotherapy, Faculty of Health Sciences, University of the Witwatersrand. $(p=0.003)$ but not significantly more than the control group $(p=0.09)$.

They had a greater reduction in weight $(p=0.004)$ which was significantly different from the Control group $(p=0.03)$. They were significantly less tired than the Control group $(p=0.008)$. The Experimental group showed a reduction in the number of patients with headaches $(p=0.05)$ and dizziness $(p=0.001)$. These changes were significant within the Experimental group but not between the two groups. The self reported risk factor modification revealed that more patients in the Experimental group could control their stress $(p=0.05)$; more were controlling their salt intake $(p=0.02)$ and more knew and were adhering to their medication regime $(p=0.05)$. Both groups showed small reductions in blood pressure. The telephonic intervention involving the support of a health-care practitioner and a family member appeared to be effective in changing aspects of health behaviour.
\end{abstract}

KEY WORDS: TELEPHONE, SUPPORT, FAMILY, HEALTH-CARE PRACTITIONER, INTERVENTION, HYPERTENSION, HEALTH, BEHAVIOUR MODIFICATION

\section{INTRODUCTION}

The South African guidelines for the management of hypertension state that pharmacological intervention should begin when persistently high blood pressures of more than $160 / 90 \mathrm{~mm} \mathrm{Hg}$ occur and for persons with blood pressures of more than 140/90 mm Hg, life-style modification should be implemented. This includes weight reduction, moderation of alcohol intake, increased physical activity, moderation of dietary salt and fats, and reduction of stress. Cigarette smoking, although not directly associated with hypertension should be avoided because it is a major risk factor for cardiovascular disease (Hypertension Society of Southern Africa 1996).

The guidelines for the management of hypertension in South Africa are however, not systematically applied by medical personnel (Daniels et al, 2000). Hypertension is not well managed at clinics in South Africa. There is little patient education and low rates of regular attendance by patients. Hence adherence to medical management is poor (Kalk et al, 2000). There are few, if any, well developed programmes in hyper- tension clinics that promote health behaviour modification.

For pharmacological and life-style modification to be effective, patients are required to adhere to a given medical intervention programme. Poor adherence to medical advice is a problematic issue in the management of all chronic diseases, and is a particular problem in lower socio-economic groups where hypertension also tends to be more prevalent and devastating in lower socio-economic groups (Meichenbaum and Turk, 1987; JNC V1, 1997).

Health belief models do not put patients into a social or family context, nor do they show how patients can be affected by interactions within a social and family context (Sotile, 1996). The Systemic Approach, suggests that patients, their families and health-care practitioners have a shared responsibility to respond to medical intervention. The focus, thus, is on the interaction between all of the above (Doherty and Baird, 1983; Harkaway and Madsen 1989). Treatment problems occur in the context of the above triad, and not as a result of the individuals concerned.
One of the most crucial individual barriers to changing health behaviour, is patients' lack of knowledge about their disease; what its consequences are, and how to look after themselves. Between $35 \%-90 \%$ of patients do not understand the information that is given to them (Prochaska et al, 1992). Patients who are treated for hypertension in the public health care system in South Africa have poor knowledge of their disease. They do not understand the causes of the disease, particularly that lack of exercise is an important risk factor (Stewart et al, 1999; Stewart et al, 2000).

The aim of this study was thus to test the effectiveness of a telephonic intervention that involved the patient, health-

\section{CORRESPONDENCE TO:}

\section{A Stewart}

Department of Physiotherapy

Faculty of Health Sciences

University of the Witwatersrand

7 York Road, Parktown 2193

South Africa

Tel: (011) 717-2064

Fax: (011) 643-4318 
care practitioner and a member of the patient's family in improving the adherence of patients with hypertension to a cardiovascular risk factor modification programme.

\section{METHOD}

Ethical Clearance for this research was obtained from the Committee for Research on Human Subjects of the University of the Witwatersrand. The Ethical Clearance Number is M970624.

\section{Study Design:}

A randomised controlled study design was used to test the effectiveness of a telephonic intervention. A Control group received an educational and home-based exercise programme only. An Experimental group received the above and the additional support of a telephonic intervention from a healthcare practitioner both to the patients and to a member of the patients' family.

\section{Patient Selection:}

The study was described to patients at a hypertension clinic of a tertiary care hospital in Johannesburg and patients were encouraged to join the study. Prior to their participation in this study, all patients signed a consent form after being fully informed about the study. Because this programme involved health behaviour modification which is independent of age, severity of disease, signs, symptoms and time since diagnosis of disease, no exclusion criteria (other than potential medical problems) were imposed on patient selection (Oldridge, 1986).

\section{Measurements:}

Baseline Data: On admission into the study patients were interviewed to obtain basic demographic data.

Medical questionnaire: A medical questionnaire was completed, to establish if there were any reasons why patients could not participate in the exercise test and exercise programme. (No patients were excluded).

Symptoms: A form was completed detailing patients' symptoms. They were asked if they experienced a particular symptom and how often it occurred.

Knowledge: A questionnaire was completed detailing patients' knowledge about their disease and what they knew about risk factor modification. The questionnaire also established the risk factor profile of patients.

Heights and weights: Patients' heights and weights were measured. The body mass index $\left(\mathrm{kg} \cdot \mathrm{m}^{-2}\right)$ was calculated for all patients.

Measurement of exercise capacity: Patients completed the six-minute walk test. Heart rate and blood pressure were measured before and after the test. The post exercise heart rate and blood pressure were measured immediately after the test was completed.

The blood pressure was measured on the left arm with the patient seated. All resting blood pressure readings were taken after patients had been seated for approximately 30-40 minutes.

All patients walked back and forth along a measured distance of 20 metres in a quiet corridor near the hypertension clinic. Patients were told to walk as fast as they could. If they needed to rest, benches were available for that purpose. They were all encouraged at 30 second intervals with the same words-"YYou are doing well, keep it up." The distance walked and the Rating of Perceived Exertion were measured after the test (Borg, 1982). Patients were on their normal medication when they undertook this test and their medication and dosages were noted.

At the completion of all baseline assessment, patients were randomly assigned into either the Experimental or Control Groups.

\section{Intervention:}

Patients in both groups were then put onto an educational and home-based exercise programme. Patients in the Experimental group had the additional support of telephone calls from a healthcare practitioner to themselves and a family member. The intervention lasted for 24 weeks.

Use of monthly visits: The educational sessions took place in the hypertension clinic of the hospital on the days that patients attended the hospital for their appointment with their doctor, or the days on which they collected their medication from the pharmacy, that is once a month. By doing this extra visits to the hospital were not required, so no additional financial burden was placed on patients.

Education: A basic educational programme was followed in which the most important aspects of management of hypertension and cardiovascular risk factor modification were discussed. In addition each patient was given a simple set of notes to take home to read. Family members did not attend the educational sessions.

The once monthly educational sessions covered the following core topics:

- what normal blood pressure is.

- what high blood pressure is.

- what causes high blood pressure and the consequences of high blood pressure.

- the concept of control of a chronic disease

- how to exercise.

- a healthy diet and weight control.

- inexpensive ways of accessing a prudent diet.

- problems associated with cigarette smoking and alcohol abuse.

- how to control stress.

- names of medication, dosages and regular medication regimen.

The educational sessions involving groups of three to four patients at a time were conducted by a physiotherapist using basic principles of adult education. Patients were encouraged to discuss their understanding of hypertension and how they coped. At each session the topic discussed at the previous session was revised before the new topic was introduced. All sessions followed the same format. At each educational session patients' blood pressures were measured and recorded.

Telephonic support: In the Experimental group only, two telephonic interventions were conducted once a month between hospital visits. One telephone call was with the patient and one with a family member. Patients' exercise programmes were checked and they were reminded about their diet and their medication. The information given in the previous educational session was reinforced. The family member was educated on cardiovascular risk factor reduction and how to support the patient. 
The telephonic interventions were conducted by the same physiotherapist two weeks after the first assessment; two weeks after each educational session and two weeks prior to the reassessment. This resulted in six telephone calls to the patients and six to a family member. Although she had a basic script to work from for the telephonic intervention, she encouraged patients and families to ask questions.

Choice of family member: The family member to be involved in the intervention was chosen by the patient.

Exercise programme: Patients in both the groups were given an individual walking programme to perform 3-5 times per week at home. A homebased exercise programme was chosen because patients could not afford to get to the hospital for additional visits and the programme needed to be flexible to fit in with their daily schedules. The length of time that they had to walk was based on the results of the six-minute walk test. Each patient was given a simple diary in which to record the days on which he or she walked. The time that they were to walk was increased on a weekly basis to a maximum of $30 \mathrm{mi}$ nutes. They were asked to return their diaries once a month when they attended the educational session. At each return visit each patient's exercise programme was discussed with him/her.

Post intervention data: Twentyfour weeks after the initial assessment, patients were reassessed. This included measurements of their knowledge and symptoms. Patients were weighed. Any changes in medication were noted. Patients' attendance at the clinic for the monthly educational sessions was taken as their adherence to the programme. Patients then completed the six-minute walk test with all measurements as before.

The author and a research assistant undertook all reassessments after establishing inter-rater reliability of the measurements taken. Neither one had been involved in the intervention. They were blinded to the data obtained at baseline and in which groups the patients were. In addition patients were not aware of what they had scored in their baseline tests.

\section{Statistical Analysis:}

To detect a clinically relevant change of 5-7 $\mathrm{mm} \mathrm{Hg}$ for either systolic or diastolic blood pressure a sample size of 40 per group had power in excess of $85 \%$ when testing one-sided at a significance level of $95 \%$ (Ebrahim and Smith, 1998).

The data were reduced using means and standard deviations. The significance of the study was set at the $95 \%$ level $(\mathrm{p}=0.05)$.

The similarity of the basic demographic data, exercise test data and patients' knowledge was established at baseline using the independent student's t-test.

Fisher's one-sided exact test was used to establish any differences in the presence and frequency of symptoms at baseline.

In addition Fisher's exact test was used to establish any differences at baseline in the following demographic variables- sex, language, education, income, current employment status and whether patients lived with their families.
Changes in adherence, knowledge, weight and exercise test data were established by using the paired t- test to detect changes within groups and the independent t-test to detect changes between groups.

Changes in symptoms were established by using the McNemar test to detect changes within groups and Fisher's one-sided exact test to detect changes between groups. Fisher's onesided exact test was used to detect changes in self-reported risk factor modification between groups.

\section{RESULTS}

\section{Comparison of Control and Experimental Groups' Baseline Data}

Clinic Attendance: Prior to the study patients in the Control group had attended the clinic for a total of 6 ((4) years and the Experimental group a total of 5((4) years $(\mathrm{p}=0.36)$.

Demographic Data: The demographic data of the Experimental and Control groups at the start of the study are shown in Table 1.

Table 1: Demographic data of the Experimental and Control groups at start of study

\begin{tabular}{|c|c|c|c|}
\hline Demographic Data & $\begin{array}{l}\text { Experimental Group } \\
(n=41)\end{array}$ & $\begin{array}{l}\text { Control Group } \\
(n=42)\end{array}$ & p value \\
\hline Age & $56.3 \pm 11.5$ & $58.6 \pm 11.2$ & $p=0.38$ \\
\hline $\begin{array}{l}\text { Population Group } \\
\text { Blacks } \\
\text { Coloureds } \\
\text { A sians } \\
\text { W hites }\end{array}$ & $\begin{array}{l}11(26.8 \%) \\
17(41.5 \%) \\
6(14.6 \%) \\
7(17.1 \%)\end{array}$ & $\begin{array}{l}6(14.3 \%) \\
23(54.8 \%) \\
10(23.8 \%) \\
3(7.1 \%)\end{array}$ & $p=0.15$ \\
\hline $\begin{array}{l}\text { Home Language } \\
\text { English/ A frikaans } \\
\text { O ther }\end{array}$ & $\begin{array}{l}29(70.7 \%) \\
12(29.3 \%)\end{array}$ & $\begin{array}{l}33(78.6 \%) \\
9(21.4 \%)\end{array}$ & $p=0.46$ \\
\hline $\begin{array}{l}\text { A nnual Income } \\
>\mathrm{R} 15,000 \\
<\mathrm{R} 15,000\end{array}$ & $\begin{array}{l}3(7.3 \%) \\
38(92.7 \%)\end{array}$ & $\begin{array}{l}5(11.9 \%) \\
37(88.1 \%)\end{array}$ & $p=0.37$ \\
\hline $\begin{array}{l}\text { Employment } \\
\text { Employed } \\
\text { Unemployed }\end{array}$ & $\begin{array}{l}10(24.4 \%) \\
31(75.6 \%)\end{array}$ & $\begin{array}{l}13(31.0 \%) \\
29(69.1 \%)\end{array}$ & $p=0.34$ \\
\hline $\begin{array}{l}\text { Education } \\
>\text { G rade } 11 \\
<\text { G radel1 }\end{array}$ & $\begin{array}{l}7(17.1 \%) \\
34(82.9 \%)\end{array}$ & $\begin{array}{l}9(21.4 \%) \\
33(78.6 \%)\end{array}$ & $p=0.41$ \\
\hline $\begin{array}{l}\text { Body W eight Kgs } \\
\text { BM I Kg.m-2 }\end{array}$ & $\begin{array}{l}78.3( \pm 19.7) \\
30.9( \pm 7.8)\end{array}$ & $\begin{array}{l}80.6( \pm 18.2) \\
31.6( \pm 6.2)\end{array}$ & $\begin{array}{l}p=0.59 \\
p=0.65\end{array}$ \\
\hline
\end{tabular}


There were no significant differences in any of the demographic data between the Experimental and Control groups.

Knowledge: There was no significant difference between the knowledge of hypertension between the Experimental $(48 \pm 14 \%)$ and Control groups $(47 \pm 15 \%)$.

Exercise capacity measured by walk test: The physiological variables measured in the six-minute walk test in the Experimental and Control groups at the start of the study are shown in Table 2

There were no significant differences in any of the variables between the Experimental and Control groups

Symptoms: The presence and frequency of symptoms in the Experimental and Control groups at entry into the programme is shown in Table 3.

There were no significant differences in the presence and frequency of symptoms in the Experimental and Control groups

The two groups in this study were similar in all respects at baseline.

\section{The Effect of the Intervention in the Two Groups:}

The results of the 24 weeks intervention in the Control group are presented first and then the results in the Experimental group.

Patient retention: There were 38 patients in the Control group who reported on their knowledge and symptoms. Thirty-six patients completed the six-minute walk test. None of the patients had had a change in medication during the 24-week period. There were 40 patients in the Experimental group who reported on their knowledge and symptoms. Thirty-eight patients completed the six-minute walk test.

Knowledge: The Control group's knowledge improved from $47 \%( \pm 15 \%)$ to $62 \%(( \pm 21 \%)$. This was a significant improvement $(\mathrm{p}<0.001)$ (Figure 1). After the intervention, the Experimental group scored $72 \%( \pm 20 \%)$ on the know ledge questionnaire. This was a significant improvement ( $\mathrm{p}<0.001)$ (Figure 1). The Experimental group had the greater

Table 2: The physiological variables measured in the six minute walk test in the Experimental and Control groups at the start of the study

\begin{tabular}{|l|l|l|l|}
\hline Physiological variable & $\begin{array}{l}\text { Experimental Group } \\
(\mathbf{n = 4 1 )}\end{array}$ & $\begin{array}{l}\text { Control Group } \\
(\mathbf{n = 4 2 )}\end{array}$ & $\mathbf{p}$ value \\
\hline $\begin{array}{l}\text { H R beats/ min } \\
\text { Rest }\end{array}$ & $71( \pm 11)$ & $71( \pm 12)$ & $p=0.98$ \\
End & $100( \pm 20)$ & $98( \pm 20)$ & $p=0.54$ \\
\hline SBP mm Hg & & & \\
Rest & $146( \pm 20)$ & $149( \pm 18)$ & $p=0.55$ \\
End & $165( \pm 25)$ & $163( \pm 21)$ & $p=0.69$ \\
\hline $\begin{array}{l}\text { DBP mm Hg } \\
\text { Rest }\end{array}$ & $92( \pm 12)$ & $95( \pm 10)$ & $p=0.32$ \\
End & $97( \pm 14)$ & $97( \pm 10)$ & $p=0.92$ \\
\hline $\begin{array}{l}\text { Rating of perceived } \\
\text { exertion (Borg) }\end{array}$ & $12( \pm 2)$ & $11( \pm 2)$ & $p=0.24$ \\
\hline $\begin{array}{l}\text { Distance W alked } \\
\text { metres }\end{array}$ & $465( \pm 97)$ & $439( \pm 102)$ & $p=0.25$ \\
\hline
\end{tabular}

Table 3: Presence and frequency of symptoms in Experimental and Control group at start of programme

\begin{tabular}{|c|c|c|c|}
\hline Symptom & $\begin{array}{l}\text { Experimental Group } \\
(n=41)\end{array}$ & $\begin{array}{l}\text { Control G roup } \\
(n=42)\end{array}$ & $p$ value \\
\hline \multicolumn{4}{|l|}{ Tiredness } \\
\hline Yes & $27(65.9 \%)$ & $23(54.8 \%)$ & \\
\hline No & $14(34.1 \%)$ & $19(45.2 \%)$ & $p=0.21$ \\
\hline$<$ twice a week & 4 (17.9\%) & $5(21.7 \%)$ & \\
\hline >twice a week & $23(82.1 \%)$ & $18(78.3 \%)$ & $p=0.50$ \\
\hline \multicolumn{4}{|l|}{ Headaches } \\
\hline Yes & $23(56.1 \%)$ & $23(54.8 \%)$ & \\
\hline No & $18(43.9 \%)$ & $19(45.2 \%)$ & $p=0.54$ \\
\hline$<$ twice a week & $6(26.1 \%)$ & $5(21.7 \%)$ & \\
\hline >twice a week & 17 (73.9\%) & $18(78.3 \%)$ & $p=0.50$ \\
\hline \multicolumn{4}{|l|}{ Dizziness } \\
\hline Yes & $20(48.8 \%)$ & $17(40.5 \%)$ & \\
\hline No & $21(51.2 \%)$ & $25(59.5 \%)$ & $p=0.30$ \\
\hline$<$ twice a week & $16(80.0 \%)$ & $10(58.8 \%)$ & \\
\hline >twice a week & 4 (20.2\%) & 7 (41.2 \%) & $p=0.15$ \\
\hline
\end{tabular}

change $(\mathrm{p}=0.04)$ (Figure 1).

Exercise Capacity: The Control group walked a distance of $439( \pm 102)$ metres at the start and significantly further, 463 $( \pm 86)$ metres at the end of the 24 week programme $(p=0.001)$ (Figure 2). The Experimental group walked a distance of $465( \pm 97)$ metres at the start and significantly further, 499((95) metres at the end of the 24 weeks $(\mathrm{p}=0.003)$ (Figure 2). The two groups were not statistically different after the intervention $(\mathrm{p}=0.54)$.

Body Weight: There was no change in the weight of the Control group after the intervention $(\mathrm{p}=0.93)$ (Figure 3). The Experimental Group had a statistically significant drop in weight from 78 $( \pm 20) \mathrm{Kg}$ to $77( \pm 20) \mathrm{Kg}(\mathrm{p}=0.004)$ (Figure 3). The drop in weight of $1 \mathrm{Kg}$ in the Experimental group was significantly different from the Control group in which there was no change $(\mathrm{p}=0.03)$ (Figure 3). 
Figure 1: Change in percentage knowledge score between 0 and 24 weeks in the Control and Experimental groups

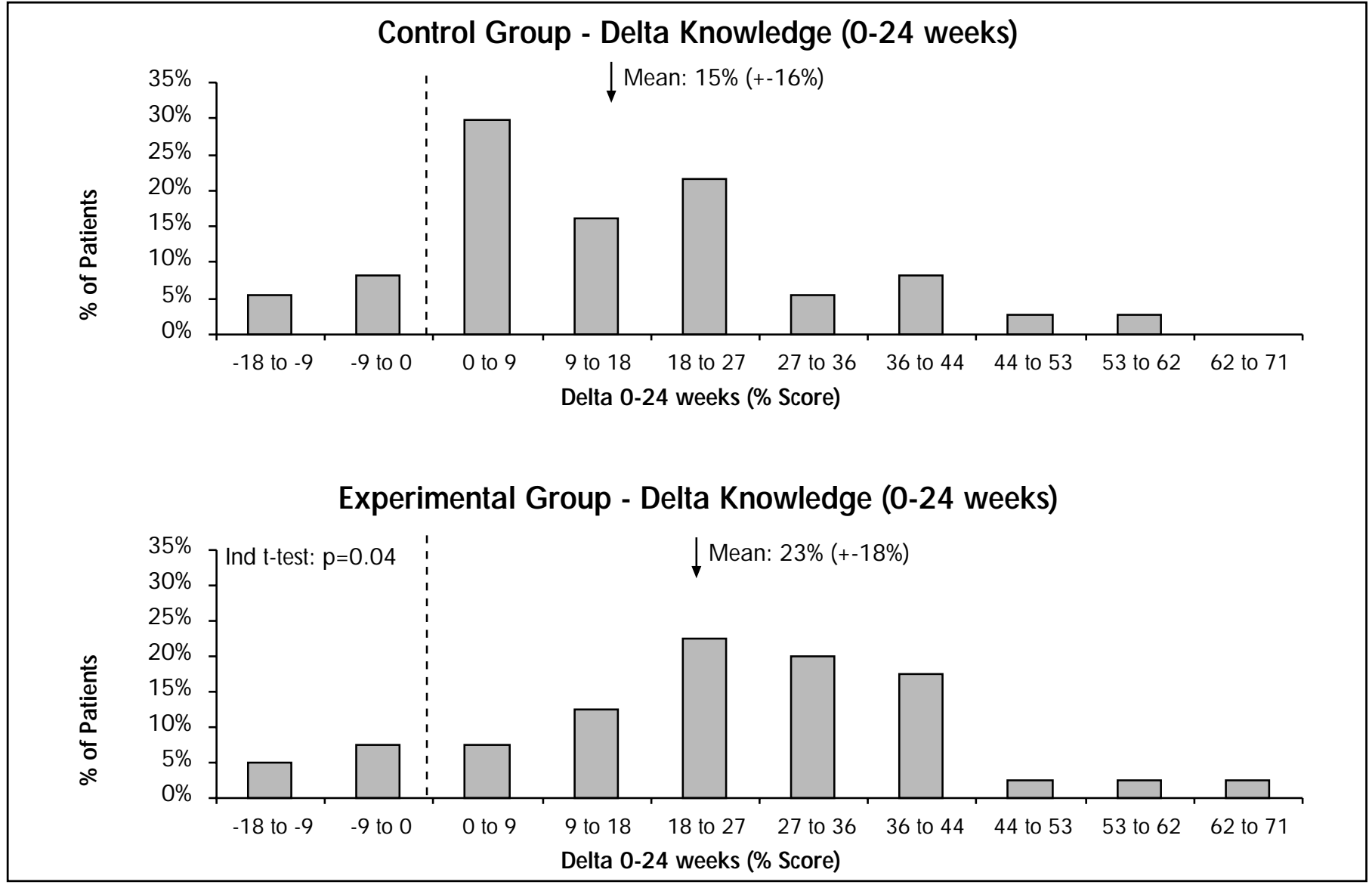

Figure 2: Change in distance walked between 0 and 24 weeks in the Control and Experimental groups

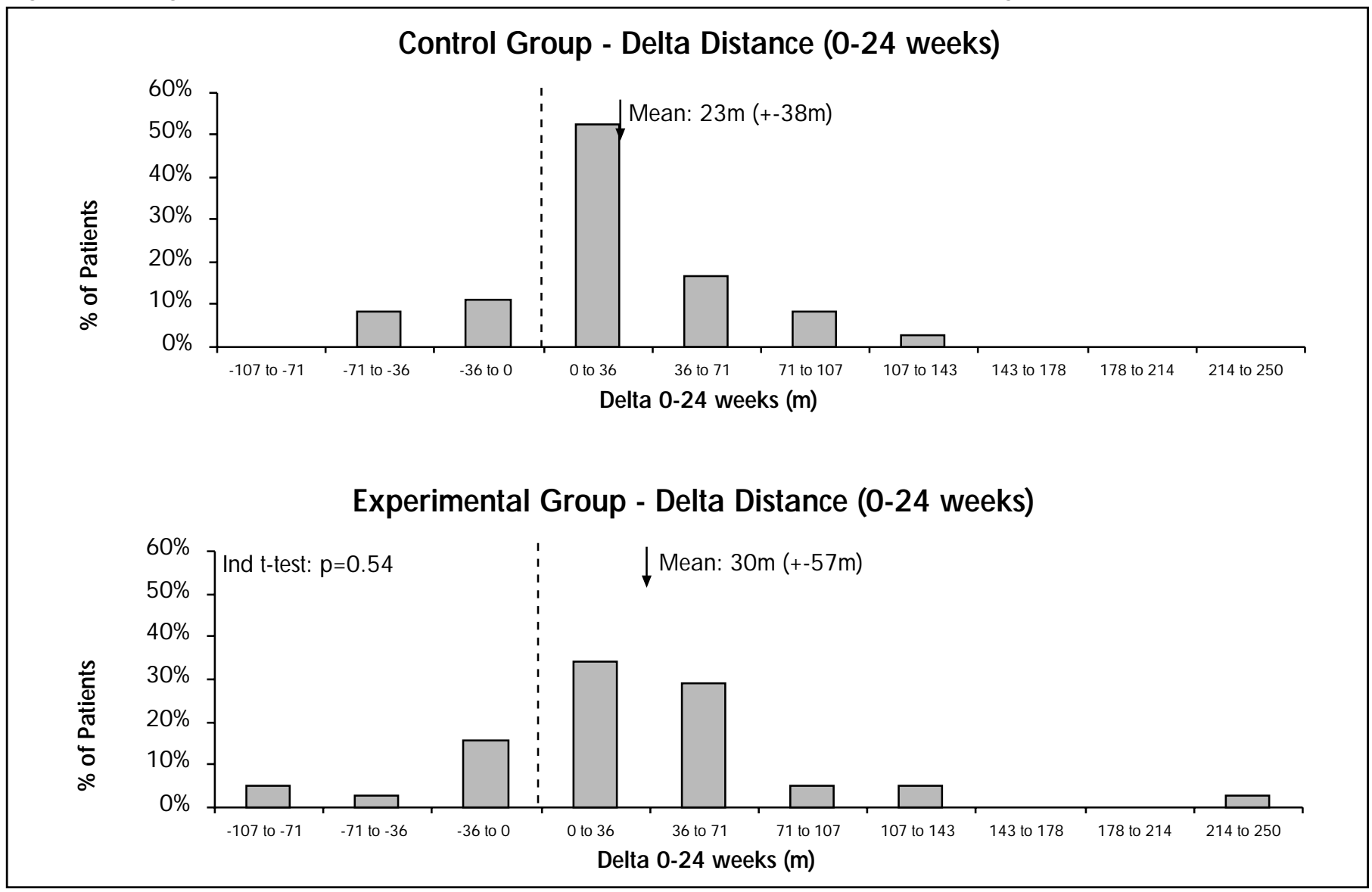


Figure 3: Change in weight between 0 and 24 weeks in the Control and Experimental groups

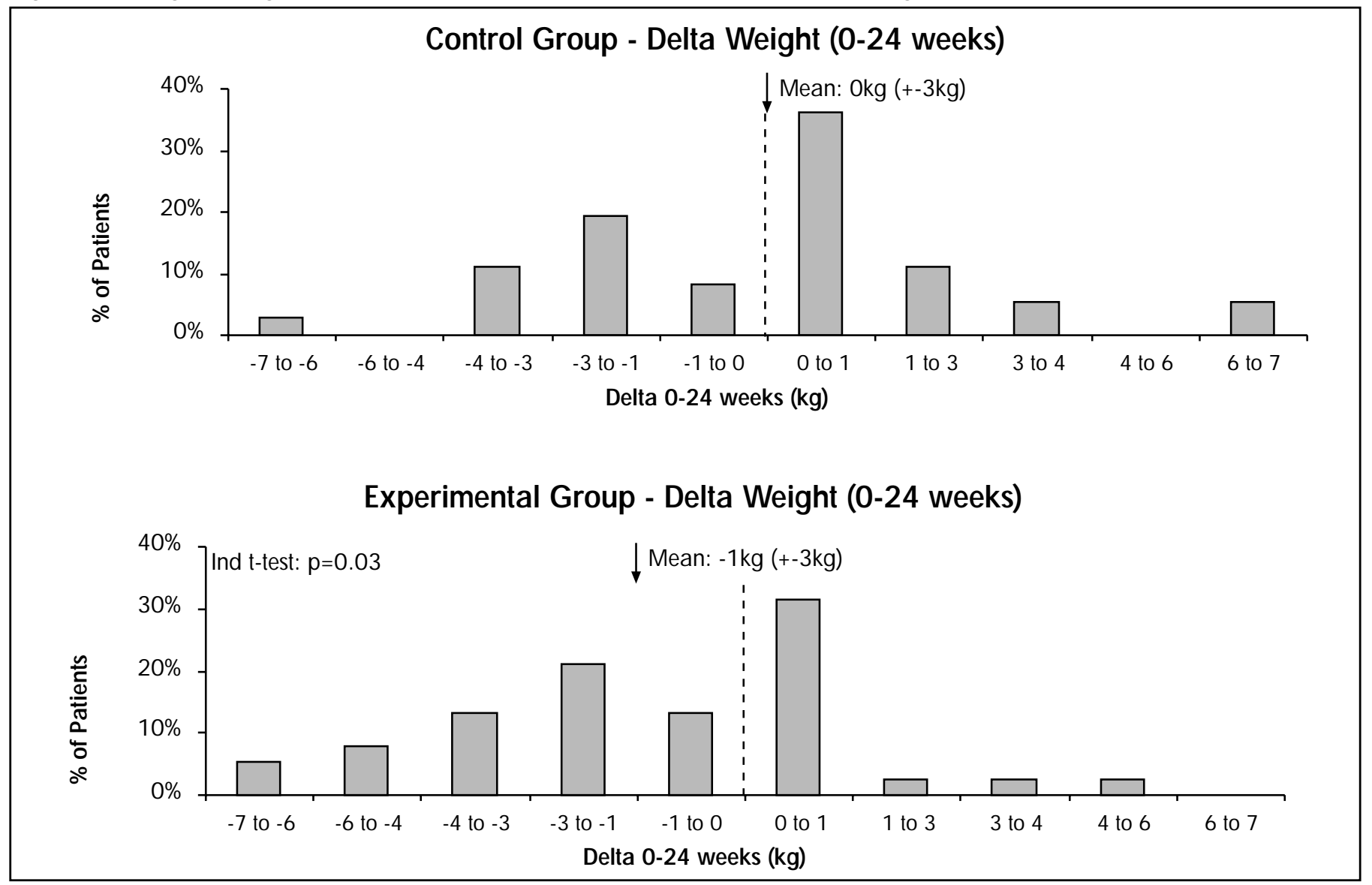

Resting systolic and diastolic blood pressure: There were small non-significant changes in the resting systolic and diastolic blood pressure in both the Control and Experimental groups.

Symptoms: The presence and frequency of symptoms in the Control and Experimental groups after the intervention are shown in Table 4. These have been compared with the presence and frequency of symptoms at entry into the programme (Table 3).

Significantly fewer patients were tired $(p=0.008)$, significantly fewer patients had headaches $(\mathrm{p}=0.05)$ and significantly fewer patients were dizzy $(\mathrm{p}=0.001)$ in the Experimental group after the intervention

(Table 3 and 4).

The Experimental group had significantly fewer patients who were tired than the Control group ( $\mathrm{p}=0.05)$. They also had fewer headaches and were less dizzy than the Control group but not significantly so.

Adherence: The adherence of $62.8 \%$ $( \pm 34.5 \%)$ of the Experimental group was significantly greater than the

Table 4: The presence and frequency of symptoms in Control and Experimental groups after the intervention that is at 24 weeks

\begin{tabular}{|c|c|c|c|c|}
\hline Symptom & Control Group & $p$ value & $\begin{array}{l}\text { Experimental } \\
\text { Group }\end{array}$ & $p$ value \\
\hline $\begin{array}{l}\text { Presence and } \\
\text { frequency }\end{array}$ & $n=38$ & $\begin{array}{l}0 \text { vs } 24 \\
\text { weeks }\end{array}$ & $n=40$ & $\begin{array}{l}0 \text { vs } 24 \\
\text { weeks }\end{array}$ \\
\hline $\begin{array}{l}\text { Tiredness } \\
\text { Yes } \\
\text { No } \\
\text { <twice a week } \\
\text { >twice a week }\end{array}$ & $\begin{array}{l}21(55.3 \%) \\
17(44.8 \%) \\
5(23.8 \%) \\
16(76.2 \%)\end{array}$ & $\begin{array}{l}p=1.00 \\
p=1.00\end{array}$ & $\begin{array}{l}14(35.0 \%) \\
26(65.0 \%) \\
1(7.1 \%) \\
13(92.9 \%)\end{array}$ & $\begin{array}{l}p=0.008^{*} \\
p=1.00\end{array}$ \\
\hline $\begin{array}{l}\text { Headaches } \\
\text { Yes } \\
\text { No } \\
\text { <twice a week } \\
\text { >twice a week }\end{array}$ & $\begin{array}{l}13(34.2 \%) \\
25(65.8 \%) \\
2(15.4 \%) \\
11(84.6 \%)\end{array}$ & $\begin{array}{l}p=0.08 \\
p=1.00\end{array}$ & $\begin{array}{l}14(35.9 \%) \\
25(65.8 \%) \\
8(57.1 \%) \\
6(42.8 \%)\end{array}$ & $\begin{array}{l}p=0.05^{*} \\
p=1.00\end{array}$ \\
\hline $\begin{array}{l}\text { Dizziness } \\
\text { Yes } \\
\text { No } \\
<\text { twice a week } \\
\text { >twice a week }\end{array}$ & $\begin{array}{l}12(31.6 \%) \\
26(68.4 \%) \\
7(58.3 \%) \\
5(41.7 \%)\end{array}$ & $p=1.00$ & $\begin{array}{l}7(17.5 \%) \\
33(82.5 \%) \\
4(57.1 \%) \\
3(42.9 \%)\end{array}$ & $\begin{array}{l}p=0.001^{*} \\
p=0.06\end{array}$ \\
\hline
\end{tabular}

$39.3 \%( \pm 42.8 \%)$ of the Control group $(\mathrm{p}=0.007)$.
Self reported risk factor modification: Risk factor modification that was 
self-reported by patients at 0 and 24 weeks is shown in Table 5. Patients reported the following:

- if they had stopped smoking.

- if they were not drinking alcohol.

- if they could control their stress.

- if they knew how much salt they could use and only used that amount;

- and if they knew the names of their medication, the dosages, and were taking their medication as prescribed.

There were no differences in these aspects of risk factor modification at the start of the programme between the Control and Experimental groups except that more patients in the Control group drank alcohol socially ( $\mathrm{p}=0.05$ ).

After 24 weeks there was a significant difference between the percentage of patients in the Experimental group who were better able to control their stress $(p=0.05)$; who were controlling their salt intake $(p=0.02)$ and who were taking their medication appropriately $(p=0.05)$ than in the Control group.

There were no significant changes in the number of patients who smoked or drank alcohol.

\section{DISCUSSION}

At the start of the programme these patients did not have the basic skills to manage their disease (Williams et al, 1998) and Stewart et al, (1999).If patients do not understand what is being said to them, they are unlikely to adhere to any form of health behaviour modification. A lack of knowledge is a considerable factor in patients' non-adherence (Prochaska et al, 1992). There are two further problems in South African hospitals. Firstly, most interactions take place in a cross-cultural context (de Villiers, 1991). Secondly the interaction between doctors, other staff and patients are very brief. (Stewart et al, 1999; Kalk et al, 2000). In situations like this, no meaningful discussion or education can take place. This was a considerable improvement in knowledge with the Experimental Group showing the benefit of the additional telephonic intervention.

At the start of the programme patients in both groups walked less than the distance described by Guyatt et al (1985) in his study, indicating the poor exercise

Table 5: Self reported risk factor modification at 0 and 24

\begin{tabular}{|c|c|c|c|c|c|c|}
\hline & Start & & & & 24 W EEKS & \\
\hline $\begin{array}{l}\text { Risk } \\
\text { Factor }\end{array}$ & $\begin{array}{l}\text { Group E } \\
(n=41)\end{array}$ & $\begin{array}{l}\text { Group C } \\
(n=42)\end{array}$ & $\begin{array}{l}p \text { value } \\
E \text { vs } C\end{array}$ & $\begin{array}{l}\text { Group E } \\
(n=40)\end{array}$ & $\begin{array}{l}\text { Group C } \\
(n=38)\end{array}$ & $\begin{array}{l}p \text { value } \\
E \text { vs } C\end{array}$ \\
\hline $\begin{array}{l}\text { Smoke } \\
\text { Yes } \\
\text { No }\end{array}$ & $\begin{array}{l}8(19.5 \%) \\
33(80.5 \%)\end{array}$ & $\begin{array}{l}7(16.7 \%) \\
35(83.3 \%)\end{array}$ & $p=0.48$ & $\begin{array}{l}4(10 \%) \\
36(90 \%)\end{array}$ & $\begin{array}{l}4(10.5 \%) \\
34(89.5 \%)\end{array}$ & $p=0.62$ \\
\hline $\begin{array}{l}\text { Alcohol } \\
\text { Yes } \\
\text { No }\end{array}$ & $\begin{array}{l}2(4.9 \%) \\
39(95.1 \%)\end{array}$ & $\begin{array}{l}8(20 \%) \\
34(81 \%)\end{array}$ & $p=0.0 *$ & $\begin{array}{l}1(2.5 \%) \\
39(97.5 \%)\end{array}$ & $\begin{array}{l}3(7.9 \%) \\
35(92.1 \%)\end{array}$ & $p=0.29$ \\
\hline $\begin{array}{l}\text { Stress } \\
\text { Yes } \\
\text { No }\end{array}$ & $\begin{array}{l}21(51.2 \%) \\
29(48.8 \%)\end{array}$ & $\begin{array}{l}21(50 \%) \\
21(50 \%)\end{array}$ & $p=0.54$ & $\begin{array}{l}27(67.5 \%) \\
13(32.5 \%)\end{array}$ & $\begin{array}{l}18(47.4 \%) \\
20(52.6 \%)\end{array}$ & $p=0.05^{*}$ \\
\hline $\begin{array}{l}\text { Salt } \\
\text { Yes } \\
\text { No }\end{array}$ & $\begin{array}{l}6(14.6 \%) \\
35(85.4 \%)\end{array}$ & $\begin{array}{l}3(7.1 \%) \\
39(92.9 \%)\end{array}$ & $p=0.22$ & $\begin{array}{l}26(65 \%) \\
14(35 \%)\end{array}$ & $\begin{array}{l}15(39.5 \%) \\
23(60.5 \%)\end{array}$ & $p=0.02 *$ \\
\hline $\begin{array}{l}\text { Meds } \\
\text { Yes } \\
\text { No }\end{array}$ & $\begin{array}{l}17(41.5 \%) \\
24(58.5 \%)\end{array}$ & $\begin{array}{l}16(38.1 \%) \\
26(61.9 \%)\end{array}$ & $p=0.46$ & $\begin{array}{l}26(65 \%) \\
14(35 \%)\end{array}$ & $\begin{array}{l}17(44.7 \%) \\
21(55.3 \%)\end{array}$ & $p=0.05^{*}$ \\
\hline
\end{tabular}

capacity of these patients. Both groups walked further during the six-minute walk test after the intervention, than patients at three other clinics in South Africa (Eales and Stewart, 1996). Considering that these patients were not exercising and did not have a history of exercising the change in distance walked in the Experimental group can probably be considered as clinically significant.

Obesity is very problematic in this group of patients. They were mostly sedentary and poor, earning less than R15,000 per year. When weight reduction was discussed with this group it became obvious that patients could not afford a prudent diet. In spite of the drop in weight in the Experimental group being statistically significant patients remained obese and the change is unlikely to be clinically significant.

It could be argued that the small changes in blood pressure are no more than the normal fluctuations seen in blood pressure readings. The small drops in systolic and diastolic blood pressure in both the Control and Experimental groups are similar however to the findings in the systematic review on non-pharmacological interventions to reduce blood pressure, done by Ebrahim and Smith, (1998).
The reduction in symptoms in the Experimental group could be due to the fact that these patients were being more careful about taking their medication and were being more careful about their diet. In addition they were also more active. Patients, as a result of the additional support of the telephonic intervention adhered better to the intervention.

Patients self reported risk factor modification was better in the Experimental Group which again was probably due to the additional support provided by the telephone calls and the family involvement.

\section{CONCLUSION}

The telephonic intervention had the effect of creating a supportive structure of patient, family and health-care practitioner. This resulted in positive outcomes in the Experimental group. The patients in this group had a better adherence to the intervention than the Control group. Their knowledge of hypertension and its management was greater. Their exercise capacity was better than that of the Control group even though the difference was not statistically significant. They lost more weight. Although this change is unlikely to be clinically significant it does constitute more health 